This is a preprint of an article accepted for publication in Journal of the Association for Information Science and Technology copyright (C) 2015 (Association for Information Science and Technology)

\title{
Impact in Interdisciplinary and Cross-Sector Research: Opportunities and Challenges
}

\author{
Daniel Gooch \\ (corresponding author) ${ }^{1}$ \\ London Knowledge Lab \\ UCL Institute of Education \\ 23-29 Emerald Street \\ London, UK
}

D.J.Gooch@bath.ac.uk

\author{
Asimina Vasalou \\ London Knowledge Lab \\ UCL Institute of Education \\ 23-29 Emerald Street \\ London, UK
}

A.Vasalou@ioe.ac.uk

\author{
Laura Benton \\ London Knowledge Lab \\ UCL Institute of Education \\ 23-29 Emerald Street \\ London, UK
}

L.Benton@ioe.ac.uk

\begin{abstract}
Impact is embedded in today's research culture with increasing importance being placed on the value of research to society. Within interdisciplinary and cross-sector projects, team members may hold distinct views on the types of impact they want to create. Set in the context of an interdisciplinary, cross-sector project comprising of partners from academia, industry and the non-profit sector, our paper aims to unpack how these diverse project members understand impact. Our analysis shows that interdisciplinary projects offer the unique opportunity to create impact on a number of different levels. Moreover, it demonstrates that a lack of accountable design and collaboration practices can potentially hinder pathways to impact. Finally, we find that the interdisciplinary perspectives that such projects introduce encourage a rich gamut of sustainable outcomes that go beyond commercialization. Our findings support researchers working in these complex contexts to appreciate the opportunities and challenges involved in interdisciplinary cross-sector research contexts, whilst also imparting them with strategies for overcoming these challenges.

\section{INTRODUCTION}

In recent years, policy makers and funders are asking researchers to provide evidence of how their research benefits the wider public (European Commission, 2014; National Research Council, 2012; RCUK, 2014). This is formalised through revised funding processes that require them to anticipate and articulate who will benefit from their research and in what ways. National and international funding bodies - including the European Commission (EC), Research Councils UK (RCUK) and the National Science Foundation (NSF) - now all include impact as a key component of their grant proposals (European Commission, 2014; The National Science Foundation, 2014; RCUK, 2014). While such mechanisms are relatively new, assessing the impact of research has always been important. Donovan (2008) and Jackson et al. (2013) both explain how the earliest measurement for establishing research impact was the peer-review process. External imperatives, however, have since broadened our understanding of impact from a concern to produce scholarly knowledge to one that additionally seeks to impact across all levels of society. The imperatives provoking these changes include transparency as to how public funding is spent, while ensuring that investment results in meaningful returns to tax payers (Donovan, 2008, Penfield et al., 2013), enhancing economic competitiveness (Donovan, 2008), the creation of public value to society (Donovan, 2008), directing research funding to areas of national interest (Donovan, 2008, Penfield et al., 2013), assessing the performance of research groups (Boaz, 2009) and establishing accountable research practices in line with promoting positive outcomes (Boaz, 2009). Early attempts of funders to introduce a broader impact component to research were premised on the notion that the purpose of science is to support a country's economy, and should be chiefly captured through economic measures. However, acknowledgement that research does not only impact on the economy but also has far reaching social implications broadened the scope accordingly (Donovan, 2007).
\end{abstract}

In parallel to shifts in how research impact is viewed, interdisciplinary research is increasingly being promoted as a route to advance the complex challenges that we face as a society (Abreu et al., 2009; Wilsdon, 2011; Sonnenwald, 2007). It is difficult, for instance, to imagine how a single discipline could address global warming. Seeking to maximise the impact of interdisciplinary research, funders are also promoting research projects that combine science with near-market innovation, through the inclusion of companies and non-governmental organisations (NGOs) hoping that research findings are translated into products and new processes (Royal Society, 2010; European Commission, 2014). These interdisciplinary - and crosssector - collaborations have complex historical, political and knowledge-based aspects that determine their success in fostering innovation and knowledge exchange (Dachtera et al., 2014). Issues such as differing goals, disciplinary chauvinism, 
This is a preprint of an article accepted for publication in Journal of the Association for Information Science and Technology copyright (C) 2015 (Association for Information Science and Technology)

and a lack of common ground have all been highlighted as problems such teams have to jointly address in order to be productive (Adamczyk and Twidale, 2007; Cummings and Kiesler, 2005; Younglove-Webb et al., 1999; Abbott, 2014).

Intentionally broad, impact definitions offered to researchers invite them to define impact in their own terms. As acknowledged by one funder: "Impacts from research can be generated through a range of diverse pathways, can take many forms, can become manifest at different stages in the research process and beyond, and can be promoted through many different mechanisms. The potential complexity and diversity of impacts from research is reflected within the Research Council assessment and reporting process." (RCUK, 2014). In the context of interdisciplinary and cross-sector research, however, it is not known how this diversity is interpreted and enacted upon, both by individual parties and during collaboration. The present paper reports on an exploratory case study of an on-going research and development project, with seven project partners from academia, industry and the non-profit sector. The research question we ask is concerned with how the diverse disciplinary and professional identities of research members encourage different understandings of impact, whether conflicts between perspectives occur, and what effect this has on the creation, management and recognition of impact. Addressing this question can contribute to our understanding of the identities and values driving interdisciplinary design. It can raise researchers' awareness of the type of challenges involved in interdisciplinary and cross-sector research, and also sensitise them to the opportunities, and how these are best pursued. In the next section, we review the literature on impact to argue that impact is both challenging to define and to capture. We then go on to highlight our approach to addressing our research question. Specifically, we turn to how the Human Computer Interaction (HCI) literature, which has long strived to foster positive change, has conceived of impact. From this collective body of work, we extract three considerations for impact based on which we then ground the analysis of our case study.

\section{BACKGROUND}

\section{Definitions on Impact}

Despite the recognition that impact is a positive pursuit, the establishment of a clear definition of research impact has remained challenging. Given the wide range of disciplines, and thus contributions, that a definition would need to encompass, it is unlikely that a comprehensive definition can be produced. The current approach instead focuses on delineating types of impact. As this is the approach used by funding bodies who evaluate research impact, there has been little incentive to consider other approaches although Abreu et al. (2009) make an attempt to define the types of impactful activities, namely people-based, community-based, commercialisation and problem-solving. Following from this position, the Australian Research Quality Framework (RQF), one of the first funding bodies to establish a definition of impact, focuses on the economic, social, environmental and cultural benefits of research (Donovan, 2008). The so called "quadruple bottom line" approach has come to dominate, with the four aspects of social, economic, cultural and environmental benefits being seen to cover the range of contributions which may be regarded as constituting impact (Bornmann, 2013).

This broad typology does not, however, recognise the complexity involved in measuring and in turn understanding impact. Some researchers in particular have described the difficulty in tying research directly to large-scale societal impact given that such impact is more likely to follow from a collective effort undertaken over time by the research community rather than from an individual research endeavour. Moreover, impact can be delayed as a result of later, enabling innovations or actors who come to recognise the significance of the research in question. An illustrative example of this is the $\mathrm{x}$-ray which, when discovered, had no practical application but now is an essential medical diagnostic tool. Furthermore, impact can be shortlived, but as in the case of the x-ray it can also be long lasting. All of these considerations raise questions regarding when and how we measure and produce evidence of impact (Boaz, 2009; Sutherland et al., 2011; Scoble et al., 2009; Penfield et al., 2013; Russell Group, 2012).

\section{$\mathrm{HCl}$ Perspectives on Impact}

The field of HCI has long been concerned with impact, evidenced in its various research strands including technologies for healthcare, inclusive education, universal design, and the developing world. A founding principle of HCI has been to ensure that end users' values are incorporated in the development of new technology (Vines et al., 2012). This has occurred at a societal level, such as for example through HCI for development, which has been concerned with the interplay between technology and socio-economic development, highlighting how technology can assist in developing countries, conflict zones and marginalized populations e.g. (Chetty and Grinter, 2007). It has also occurred at an individual level through, for instance, communication technologies that have bridged together individuals, strengthening social capital with particular benefits to those with low self-esteem e.g. (Steinfield et al., 2008). Conducting a critical analysis of the HCI literature, including a 
This is a preprint of an article accepted for publication in Journal of the Association for Information Science and Technology copyright (C) 2015 (Association for Information Science and Technology)

focused review on research awarded the prestigious SIGCHI Social Impact Award ${ }^{1}$, we show that discussions on impact have centred around three key considerations: (i) outcomes and processes, (ii) beneficiaries and (iii) sustainability. Examples include Gregg Vanderheiden's work on producing accessible technology (outcomes and processes, see Vanderheiden and Jordan (2006)), Allison Druin's focus on designing technology with children (beneficiaries, see Druin (2002) ) and Gary Marsden's work on HCI for developing nations (sustainability, see Gitau et al (2010)).

\section{Outcomes and Processes}

A first strand of research has discussed impact either as following the use of technological artefacts, or as an outcome of the technology design process. Historically, HCI researchers have sought to create impact through the introduction of new technology. Such work has commonly investigated the interaction between technology and people, observing the benefits of technology as its main impact. This research has yielded numerous examples of positive change, such as for instance, minimal manuals that have altered the way in which nearly all manuals (for both technological and non-technological systems) are written (Carroll et al., 1987); the do-it-yourself mantra of Ikea would be difficult to defend without this advancement. Another example is the Scratch programming language for children (Maloney et al., 2010). Used in more than 150 different countries, Scratch has changed how children are taught basic programming principles. At present, 6,233,958 projects have been shared through the worldwide Scratch community ${ }^{2}$. The tool has also become a key component of the implementation of the new national computing curriculum in many primary schools in England ${ }^{3}$ providing evidence for the impact this research has had on teaching and learning.

Yet, while impact can be the outcome of technology use, as Friedland and Yamauchi (2011) point out, it is imperative to recognise that design processes can lead to new knowledge and learning, and thus create new pathways to impact. Participatory Design (PD) is an approach that explicitly recognises this by involving users in technology design processes, while creating opportunities for mutual learning and personal development both for intended users and designers (Carroll et al., 2000). From the perspective of intended users, a representative example comes from child-computer interaction research where it is pointed out that participants and future users involved in the process of design acquire new skills as well as specific domain knowledge. In the words of Guha et al. (2010) "the impacts reported on child design partners are nearly universally positive, including children being empowered, feeling challenged, increases in communication, collaboration, confidence and problem solving skills, and learning about technology". From the perspective of designers, on the other hand, human-centred design practices, such as $\mathrm{PD}$, can provide insight into the design problem and open up new perspectives, in turn enabling designers to advance novel and relevant solutions (Fallman, 2003).

\section{Beneficiaries of Research}

A second strand of research has been concerned with defining who benefits from research. Vines et al. (2013) have argued that who participates and in turn benefits from research can be a political matter, one that is defined a-priori by researchers but also determined by funders. Moreover, pragmatic issues such as the lack of wider engagement of potential 'beneficiaries' can limit participation and privilege certain groups. As a consequence, the same authors call for more transparency regarding how certain groups become involved and how this involvement is managed against other competing agendas. Design frameworks such as learner-centred or informant design, have been developed to lay out clear roles that in turn can be used to articulate the benefits for those who participate in the design process (Good and Robertson, 2006). While such planning is motivated by the purposeful nature of design work, other research has shown beneficiaries to span beyond those who participate in the research directly. While developing educational technology for schools, Bossen et al. (2010) found that teachers who participated in design engaged in self-motivated forms of knowledge exchange within their peer networks, as a result broadening the beneficiaries of the research. They observed that "not only are ideas and initiatives disseminated directly within the organization, but also through networked relationships among people, stretching across organizations and project groups". In this instance, the beneficiaries extended beyond the teachers connected to the research project to include teachers within the peer-network of the intended beneficiaries. The importance of unplanned beneficiaries has also been acknowledged more broadly by Sengers and Gaver (2006) who argue that technology must be designed to invite interpretation, a decision that in turn encourages the engagement of new beneficiaries.

\section{Sustainability}

A third strand of work has attempted to understand and influence sustainable impact, i.e. impact which continues beyond the end of the research project. Researchers, and research participants alike, have often bemoaned that novel initiatives tend to fade upon the end of research projects (Bossen et al., 2012). Sustainability necessitates a plan for continuity on the part of the researcher once the research project has ended. Emphasising the challenges required to support this continued effort, Taylor

\footnotetext{
${ }^{1}$ http://www.sigchi.org/about/awards/
} 
This is a preprint of an article accepted for publication in Journal of the Association for Information Science and Technology copyright (C) 2015 (Association for Information Science and Technology)

et al. (2013) point out that research prototypes are not typically finished products, voicing concern that "far from being a benefit for the community, a technology that is difficult to support while not being perceived to offer value can instead be a burden" (also Oostveen et al., 2013). One possible reason for this is offered by Edwards et al. (2010) who observe that most HCI systems are built upon pre-existing technical infrastructure (e.g. Ethernet) with the HCI community exerting little influence on the design of infrastructure itself. This can cause many projects to "work around" the infrastructure, using it to achieve things it was not designed to do. In the context of impact, it thus raises the question on how sustainable technologies can be if the infrastructure they rely upon is not itself usable (Merkel et al., 2004; Taylor et al., 2013).

For this reason, it has been argued that inventions alone do not lead to change (Jackson et al., 2007, Edwards et al., 2007, Ribes and Finholt, 2009) and that sustainability requires a broad ensemble of techniques and practices, institutional commitment, policy changes and participant expertise and training. Given the complexity of these actions, Ribes and Finholt (2009) point out that sustainability cannot be planned at the end of a research endeavour, but instead needs to be embedded across all of its stages. They go on to identify institutional and policy barriers to sustainability, such as the limited funding and time afforded by funding bodies for such actions and the lack of currency of sustainability within academic institutions in terms of reputation or career progression.

\section{METHODOLOGY}

\section{Research Approach}

While the HCI community has highlighted three key considerations for impact, it is not clear how impact is conceived by those in other disciplines, or sectors and indeed how different conceptualisations within such diverse projects co-exist and direct individual as well as collective practices. To explore this question, we undertook an exploratory case study on a European Commission (EC) funded research project that involved partners from academia, industry and the non-profit sector. Our epistemological position was rooted in interpretivism, i.e., an understanding that phenomena happen through personal interpretation and construction of meaning with the truth differing from person to person (Geertz, 1994; Rosen, 1991). Interpretivism recognises the legitimacy of different perspectives on impact and how they might be rooted in participants' values. Our case study is thus concerned with a single case of an interdisciplinary project and the individual researchers involved. Case studies are in-depth investigations of a phenomenon in its real life context, where the researcher has no control over events that shape researchers' understanding of impact (Yin, 2014). Case study research aims to illuminate a set of decisions, exploring why they were taken, how they were implemented and with what result (Schramm, 1971; Flyvbjerg, 2006). This approach was well suited to support our exploratory goal to understanding how impact is conceptualised at an individual level, socially negotiated and managed within our interdisciplinary, cross-sector project.

\section{Research Context and Goals}

The research took place in the context of an on-going 3-year technology-enhanced learning project funded by the EC. The aim was to develop a tablet-based Intelligent Tutoring System (ITS) to help children with dyslexia aged 9-11 years to improve their literacy. Supporting this age group was particularly important as these children will shortly begin their transition from primary to secondary education. This transition results in substantial increases in the amount of text they need to read and often reductions in the level of individualised support they receive. The ITS is a tablet-based application consisting of two main components: a reader with an adaptive presentation of text and an educational game integrating a series of learning activities, with both of these components connected to a user model. By tracking the individual difficulties a given child may have, the ITS was envisioned to provide targeted support. For example, while one child may be presented with learning activities that target their difficulty with suffixes and prefixes, another may be given support with syllables and vowel sounds.

Our research proposal was submitted at a time when impact was not part of the EC's application process. Impact was thus expressed at the proposal stage both in the form of interventionist goals of improving literacy and as part of a broad exploitation and dissemination work package. Additionally, with the exception of the UK where impact was at the time being introduced within the funding application process, funding schemes in other partner countries did not require the articulation of an impact component. Regarding legal aspects, given the research focus of the project, the intellectual property rights were shared across the consortium from the onset, and as such are less likely to have shaped participants' focus toward a particular technology outcome.

\section{Project Participants and Interviewees}

Project partners included five academic institutions with expertise in HCI, game design, psychology, linguistics, education, artificial intelligence and software engineering. The authors of this paper were participants in the project representing the discipline of HCI. Additionally, the project included an industry partner with expertise in developing assistive technology and 
This is a preprint of an article accepted for publication in Journal of the Association for Information Science and Technology copyright (C) 2015 (Association for Information Science and Technology)

a non-profit organisation whose key competence is dyslexia specialist teaching. We interviewed a cross section of project partners, seven in total, with the goal to capture the diversity of cross discipline and sector perspectives. Although we approached each partner, it was not possible to interview participants at each site. Five participants were male and two were female. Out of the seven participants, six had previously worked in interdisciplinary research projects. Interviews lasted between 25 minutes and one hour (average: 45; SD: 14).

In what follows, we provide a description of project partners' disciplines, roles in the project and professional contexts. We also indicate the profile of the seven people we interviewed. Given the multinational nature of the research collaboration, we recognise that there may have been possible cultural influences, which however our study did not examine and we thus leave to future research. During the project proposal stage it was necessary to stipulate work packages and leaders based on relevant expertise. In the initial stages of the project, this encouraged a collaboration characterised by "knots" where members were loosely connected and their roles were fixed (Engeström et al., 1999). However, the fixedness of these knots changed as the collaboration progressed and we thus report partners' roles in the project as they had formed at the time of the case study.

HCI, Academic (HCI-AC; Project Participants=3; Paper authors): The HCI discipline/academic sector had an embedded role across the project. HCI-AC was involved in the user requirements phase supporting design decisions with user research, was in charge of the specification for the user modelling component of the software and led one strand of the technology evaluation. The team included one mid-career academic working in the area of interaction design and two early-career researchers (post-docs) with a similar background.

Gaming, Academic (Game-AC; Project Participants=3; Interviewees=2): The gaming discipline/academic sector was tasked with developing the adaptive game component of the educational game, which would personalise the content and activity to a child's needs. Additionally, this partner was the lead for the game design narrative and storyline that would combine best practices in game design with pedagogical design. Game-AC was represented by two interviewees, belonging to the same games research group, who were the leaders for these components: an early-career researcher (post-doc) working in the area of affective computing and a mid-career academic working in the area of game design studies and interaction design.

Technical, Academic (Tech-AC; Project Participants=4; Interviewees=1): The technical discipline/academic sector was responsible for the infrastructure of the technology including setting up a server that would interface with the game, creating front end tools for teachers and implementing the user profile. Tech-AC was represented was by one interviewee, a latecareer academic with a computer-science background who was also the technical coordinator of the project and was thus accountable for the delivery of the technology.

Special Education, Non-Profit and Academic (SE-AC and SE-NP; Project Participants=4; Interviewees=2): The special education discipline was in charge of the user requirements for the technology outlining the pedagogical design and the final evaluation of the technology with children. SE-NP was represented by two interviewees from the non-profit sector who led on both efforts: an early-career researcher with a background in linguistics and a mid-career dyslexia specialist teacher employed by the non-profit organisation to work on the project.

Innovation, Industry (IN-SME; Project Participants= 3; Interviewees=2): The innovation/industry sector partner assumed the day to day management of the project, supported the Tech-AC partner at critical moments, and also led the exploitation strand of the project. IN-SME was represented by the director whose role was to manage innovation in the company and one of the senior technical leads who implemented innovation plans within the company.

\section{Methods and Analysis}

The interviews took place 18 months after the project had begun, thus allowing us to understand how perceptions of impact aligned with project partner values and practices during this period of time. Each interview was semi-structured, consisting of two parts. In a first, warm up phase, participants were probed on their initial involvement in the project, what they hoped the project would achieve and what type of outcomes they wanted from the project at the onset. In a second phase, we showed participants the Research Councils UK "Pathways to Impact" document, which provides concrete routes to impact (see Figure 1; RCUK, 2014). This document has been designed to be intentionally broad and thus offered a common reference point that was malleable to discussions of impact. Participants were asked to detail (i) the types of impact the project was achieving, (ii) whether the project was achieving additional impact to that covered in the pathways document, (iii) what activities the project was undertaking to achieve its impact and (iv) which type of impact was most important to them personally and why. 
This is a preprint of an article accepted for publication in Journal of the Association for Information Science and Technology copyright (C) 2015 (Association for Information Science and Technology)

With the participants' consent, the interviews were recorded and transcribed for analysis. A thematic analysis was conducted, directed by our three key perspectives on impact (processes and outcomes, beneficiaries and sustainability). The focus of the analysis was on how different participants conceived of impact, oriented their individual practices to their perspectives on impact, and how they negotiated their expectations of impact at a group level. As part of the interpretive process, the interviews were triangulated with our knowledge of participants' decisions in the project, group discussions that bore implications on impact, and project communiqués.

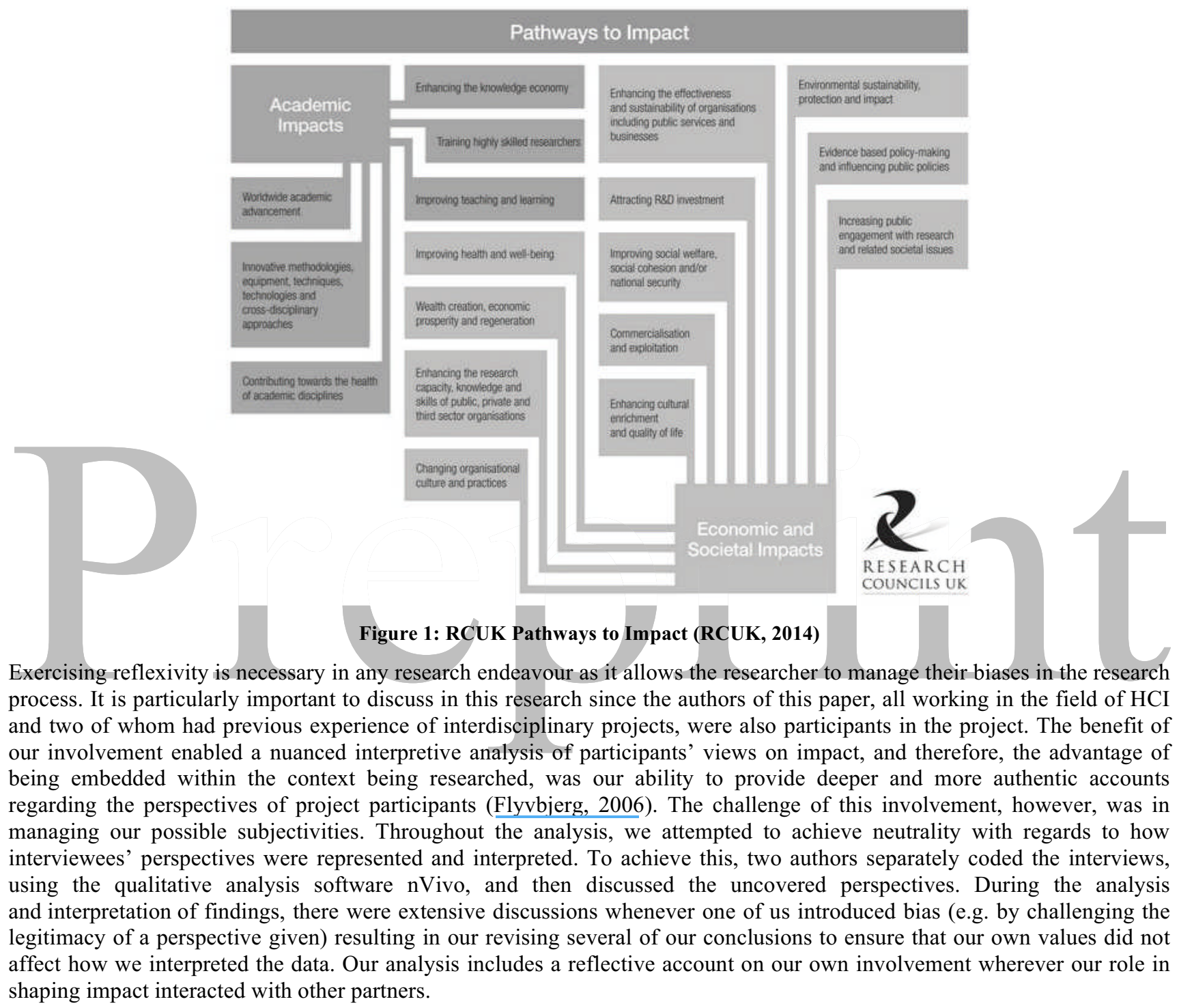

\section{Ethics}

Anonymisation is challenging to carry out in qualitative research and measures taken to safeguard it often depend on the context of the research. Our participants completed a consent form where it was made clear that the results of our study would be written up for academic publications. Despite this, shedding light onto contrasting views on impact could be a sensitive topic that potentially disrupts collaboration within our project. Similar to what has been argued in previous research (e.g. Shkolvski and Vertesi, 2013), in anonymizing the data such that individual participants remain unidentifiable, researchers' goal - in this instance, to attribute differences to interdisciplinary or cross-sector views on impact - can be made impossible. While by no means do we claim to fully secure the anonymity of our participants, a decision was made not to directly attribute quotations and refer to all participants with the female pronoun. Following from Shkolvski and Vertesi 
This is a preprint of an article accepted for publication in Journal of the Association for Information Science and Technology copyright (C) 2015 (Association for Information Science and Technology)

(2013) we additionally removed references to the project name from this article to inhibit discovery from targeted project searches.

\section{RESULTS}

Our thematic analysis yielded three key themes presented in this section. 'Outcomes' focuses on how participants understood the impact of the technology being developed for specific beneficiaries. 'Processes' explains the tension between developing the technology and affording more time or resources to support process-based impacts promoted within specific disciplines, showing that negotiation of these tensions can depend on cross discipline knowledge exchange. 'Sustainability and long-term impact' captures a holistic perspective of sustainable and long-term impact types, showing that commercialization in particular requires an overhaul in the design and development process.

\section{Outcomes}

\section{Evidence of Outcomes}

All of the interviewees agreed that the main outcome of the project was the production of tablet-based software that would impact on learners with dyslexia by supporting them to acquire literacy skills. However, in discussing with project partners the ways in which the technology would contribute learning gains, two contrasting views emerged. The first was motivated by a deterministic perspective on technology, positing that technology would inflict change and contribute to students' learning. As the Special Education Non-Profit (SE-NP) partner pointed out: "I wanted to come out of the project with a piece of technology, which I could use with students who would really love to play it and accidentally learn how to read as a consequence of playing it'. In line with this, during project meetings, the SE-NP partner advocated the view that children's affinity with technology would naturally foster independent learning. Taking a similar viewpoint on technology, the Technical Academic (Tech-AC) partner discussed the measurable gains she expected in students' learning: "This is a learning tool so basically the change is supposed to be learning of reading and writing."

Conversely, the HCI Academic (HCI-AC), as well as one of the Gaming Academic (Game-AC) partners, all working in the area of interaction design, favoured a social constructivist view of technology, acknowledging the need for meaningful consideration of context and positing that technology is useful insofar as it is used appropriately and creatively by students and teachers. In defending this view, the Game-AC partner brought attention to the challenges involved when assuming that learning gains are attributable to technological interventions:

\section{"I think we need to be aware that impact for this system won't be totally stand alone. We shouldn't talk about it as a stand alone thing. It happens in concert with extra support, extra attention, parental support... [i.e.] other activities that take place outside of the software."}

These two perspectives framed impact in distinctly different ways, introducing unique lenses onto how technology should be deployed and what evidence is important to gather. The former ended up prioritising a research design that measured literacy skills periodically during students' technology use without explicitly focusing on how technology is being used. The latter led to a participatory method that focused on the learning process encouraging reflective uses of technology for learning and teaching by directly involving teachers in the evaluation as 'designers'. Grounded in the academic literature on technology enhanced learning, those who advocated a designer role for teachers provided research evidence supporting their claims. Nonetheless, project partners in special education either favoured a positivist epistemology that privileged different methodologies, or placed more trust in their own expertise. These views did not converge and instead partners agreed on a two-tier evaluation plan with different pathways to impact.

At the time of the interviews a firm evaluation plan had been proposed. However, our interviews revealed a general sense of doubt amongst project partners as to what constitutes evidence and how this can be measured. The Game-AC partner played a critical role in developing a fine-grained user modelling and adaptation component for the software. Yet, she talked about the learning outcomes of the software in broad terms, highlighting children's improvements in reading skills and general life improvements, noting that we may not know how to assess these aspects. The SE-NP partner believed the software to be an additional teaching resource, with a strong pedagogical underpinning and with a wider array of outcomes to those measured by the project such as for instance its ability to re-engage learners in reading. In her view, the product would be worthwhile regardless of what an upcoming evaluation of the software would reveal. Taking a more conservative approach, the Tech-AC partner was hesitant to propose new outcomes pointing instead to the research proposal and to designated "expert" project partners from the SE-NP partner: "I think, the educational experts, [project member names] are the persons to talk better about it [the outcomes]". 
This is a preprint of an article accepted for publication in Journal of the Association for Information Science and Technology copyright (C) 2015 (Association for Information Science and Technology)

\title{
Adoption
}

Even though collecting evidence about the software's effectiveness was perceived to be crucial, a number of partners argued that impact would follow from the software's real world adoption. The commercial and innovation perspective of the Industry (IN-SME) partner meant that they favoured a fully developed piece of software that was of near commercial quality and that demonstrated "added value" through its adoption. The pathway to adoption for the IN-SME partner was to create a stable product that had shown learning gains during the evaluation, indicating that the software had some impact on the students using it. This product could then be sold using their typical sales process. In discussing this, the focus was less centred on the type of impact the software would have on children, with more weight given to the importance of first introducing cultural change in schools and shifting inertia around dyslexia. Focusing on the technology gatekeepers, this partner believed that the mobilisation of teachers, head teachers, teaching assistants, IT support and librarians was imperative to successfully introduce technology as a vehicle for change. As the IN-SME partner explained:

\begin{abstract}
"I just find frustration in the education system amongst teachers and TAs and Heads. They are just not engaged in this issue [dyslexia] ... and I think that the biggest potential this project has is that it actually can act as a tool for change in the education system. If you've got a portal aligned to methodology, aligned to a set of tools that can show them how to bring about change in an efficient way, they might get involved and run with it... Right now in schools, teachers have a prejudice about the make up of a class. They think that in every class of 30, there's 5 smart ones, 5 dumb ones and there's 20 in-between... and nothing that we say seems to change their view on that... and I just don't believe that's the case."
\end{abstract}

Other partners circumvented these cultural barriers and approached the same concern by proposing to build upon existing networks. In line with their practitioner focus, the SE-NP partner concurred in wanting a product of commercial quality, so that they could reliably use it with students within their teaching centres across the United Kingdom. The Tech-AC partner advanced the view that the technology would be used by focusing on beneficiaries from their professional network to address their specific needs:

"I can very easily imagine what we are building to be used either on it's own exactly as we produce it, or with slight modifications. We take out a few parts and perhaps add some others in order to take into account local requirements... We can very easily customise the product and support it so it is necessarily commercial, but there will be components that we can make available to begin with to the partners; those who have worked on the project, so our collaborators... I know people who would like to use it. [Partner name] is willing to think about it [as part of intervention sessions]. The feedback I am getting from [a non-consortium collaborator] was very positive as well."

\section{Processes}

Processes Subservient to Outcomes

The project was managed by the Tech-AC partner who advocated a process that defined software development as the highest priority. To this end, she had put together a team who had the required technical and pedagogical expertise. This project partner's approach was to ensure a close coupling between process and outcome, focusing on achievable, tangible short-term targets. Besides her anxiety of managing a strict timeline, the subservient role of processes to outcomes was further driven by the managing Tech-AC partner's belief that the project's impact stemmed from the technological artefact being developed rather than the knowledge gained through the process of designing it, or the impact on those participating in such processes:

"We have learned about how to design things that academics care about, [e.g.] how users like games... I would rate them secondary to the other advancements. Most probably I am biased there because I prefer to see the impact on real people... [In PD] there is a small impact [on participants] but it is a tiny one because we have a very small group that we talk to... [PD] it's not a cultural experiment".

\section{Discipline-Focused Impacts}

Despite this top-down instrumental view on process, other project partners aspired to foster impact through design processes. In particular, HCI-AC advocated and pursued a PD approach that involved children and teachers in the design process. This approach was driven by researchers' emancipatory values, with a view to advance academic knowledge with new PD processes for working with neurodiverse children and knowledge about game design. The decision to share control with end users not only foregrounded the design process, but it also challenged the specified roles instituted by the managing Tech-AC partner, most importantly the assumption that domain experts could act both as designers and as advocates to children's needs, a view that had been advocated by the Tech-AC partner at the proposal stage. Recognising that their approach to design could cause conflicts within the project, the authors approached a member of the Game-AC partner who was sympathetic to PD. After conducting a series of PD workshops for the game component of the software with more than fifty children in the UK, they shared with other project members video captures of children's involvement, vividly illustrating 
This is a preprint of an article accepted for publication in Journal of the Association for Information Science and Technology copyright (C) 2015 (Association for Information Science and Technology)

children's empowerment and resultant game ideas. Observing the value of PD through example allowed other project partners to identify with different aspects of PD and to accept PD as part of the project's design process. Special education partners recognised the creative outlet of PD as part of their own teaching practice and volunteered to replicate design workshops with fifteen children in Greece. Experiencing children's empowerment first hand transformed them from neutral parties into strong advocates of children's role in design. Initially sceptical about PD, the Tech-AC partner also came to appreciate the mutual learning it encourages: "The children you [HCI-AC] visit at school, the parents as well... all these things [participatory activities] increase the public awareness in research at some point and change the attitude."

While PD processes were successfully embraced within the project, the Game-AC partner, whose goal was to develop new affective modelling algorithms toward impacting on the field of AI, experienced insurmountable difficulties in instituting her process. The Game-AC partner's method required the participation of a large number of children who would play the gaming component of the software, to subsequently train AI algorithms:

"Our standard process would have been to take lots of children and try to model things like frustration, try to model confusion, try to model confidence from different modalities and then use those models to direct adaptation in a single way."

This approach offered limited empowerment to children and placed emphasis on rigorous objective measurement of children's emotions. The lack of a direct link between this partner's intended academic impact and impact on children's literacy skills, the limited empowerment the proposed method offered to children, and the methodological requirement for large number of users meant that project partners whose role was to recruit child participants were hesitant to support this work. These obstacles forced the Game-AC partner to take a more conservative direction that relied on self-report measures from a small sample of teachers. Highlighting the divergent processes involved in the design of complex systems, the GameAC partner argued:

"With these collaborations you can really only control your own process and you can hope that other people will use processes that work with yours or that complement yours... But I'm also quite aware that in these EU projects, that's pretty unrealistic. Especially since they also seem to be - the way they are worded - they seem to be worded in a way to try and mix up groups of people who don't necessarily have similar ways of working."

Taking this argument further, we found that task interdependencies between partners meant that those who wanted to advance domain-specific processes in support of the project's instrumental goals were required to engage in a process of negotiation with other project partners. Individual control over one's process depended on other partners' acceptance of the process and was thus not guaranteed.

Researcher Knowledge and Learning

The impact of the design process on the researchers was highlighted by all of the interviewees. Both the IN-SME and SE-NP partners had entered the project with the expectation that knowledge gained through the project would advance their organisational culture. Looking to strengthen their in-house expertise in research, the IN-SME partner solicited opportunities for PD training by the HCI-AC team. Additionally, their access to domain knowledge on dyslexia led them to make changes in their existing product line. As a member of the team explained, "I thought I had a fairly good knowledge about problems with dyslexia... I have picked up more and more during the project, really useful and some of the things we have already adopted into our products." The SE-NP partner, on the other hand, wanted to explore interventions (such as the one pursued within the project) that supported learners to solve real problems they faced with reading text. In the course of the project, however, she also learned how to effectively collaborate with technologists:

"My lesson learnt, partly through this project I think, is always to draw pictures... Lists of features are useless because different people mean different things by them... So, [you] always have to have a picture of a screen and an arrow saying 'click on this button' and this is what that button does... If only when - if and when you have that can you actually get a product where people are looking at something which does something and makes sense rather than start speaking in generalities... My lesson learnt is that every project needs to start with pictures."

Similarly, the Game-AC partner described collaboration and project management skills that had resulted from her participation:

"I have learnt to manage and coordinate a project at a university level... I have learnt how to interact with other partners within a European project, which is, everything was, new for me... It's a bit self-continuous since you are mostly trying to work on more European projects but I guess most of the skills will transfer as well." 
This is a preprint of an article accepted for publication in Journal of the Association for Information Science and Technology copyright (C) 2015 (Association for Information Science and Technology)

Despite the recognition that such learning was happening, most interviewees emphasised that this knowledge was secondary to the main aims of the project, and in the view of the Game-AC partner, its professional significance was limited.

\title{
Sustainability and Long-Term Impact
}

\section{Sustainability of Technology}

Our interviewees were polarised on whether the project should result in a piece of sustainable software, i.e., a piece of software that is usable beyond the end of the project. Given their professional context, the SE-NP and the IN-SME partners entered the consortium with the assumption there would be a commercially viable product that would have impact at scale. As the SE-NP partner explained:

\begin{abstract}
"My initial expectations [were] partly because of the IN-SME partner's involvement and the way the initial meetings were run where the IN-SME partner played a bigger role. My sense was that this was going towards a product and in some ways it came as a bit of a shock in the middle [of the project] that lots of people from Universities were saying 'well really it's a research project'... But we've kind of made our peace with that and we are just happy to get something out of something."
\end{abstract}

Standing in the way of sustainable software, however, were professional and pragmatic obstacles. Given the research focus of the project, the consortium was comprised primarily of academic partners. While interviewees from the academic sector all expressed a commitment to developing a usable, high quality prototype, their primary contributions resided in their respective fields. As the Game-AC partner pointed out, "I know that the EU would like us to go off and commercialise these things. I think ultimately that's what these projects are about, but as a researcher that's not what is interesting to me about this." As a consequence of this, academic project partners had little willingness to contribute time to activities they viewed as secondary to their professional progress. While the Tech-AC partner discussed in length the importance of exploitation, she attributed this responsibility to the IN-SME partner rather than recognising that exploitation requires embedded, on-going design and development processes that all project partners must follow. For example, despite knowledge of the particularities of school network infrastructures in the UK, the Tech-AC partner advocated technical decisions that challenged whether this product could run in UK schools, or indeed sustained past the end of the project, thus necessitating a substantial overhaul of the software if a commercial route was later pursued.

Research Prototypes Promoting Long-term Impact

In contrast to those who conceived of long-term impact as a consequence of a sustainable product, the managing Tech-AC partner defended the role of research prototypes in ways that other project partners had not considered. From her perspective, even if the technology was not implemented in the most optimal way, its individual components could stimulate future research by industry and inspire new tools. Thus, the mere presence of technology constituted an opportunity for further innovation. Additionally, the prototype could be used as input to dyslexia specialist teaching by providing a platform for large-scale experiments. As she explained:

"For example, we have lots of learning activities, which are appropriate and some of which may be more effective than others. Also, [there is] the order in which we have placed these activities, or in the profile. All of these things we can evaluate by changing the order and running experiments... Psychologists on the project can propose several hypotheses that we can evaluate using this tool. It is a learning thing... It is no longer an engineering issue or a software issue. The research outputs [impacts] will be in the field of linguistics."

Looking at the project from a macro perspective, the Tech-AC partner approached it as one in a series of many supporting a longer-term effort that helps policy makers and schools to understand how technology can be developed to support children with dyslexia.

\section{Non-Technological Sustainable Impacts}

Interviewees made a distinction between the impact that would result from children's use of the technology within the remit of the project and tangential sustainable outcomes following from other project activities. These sustainable outcomes were often emergent, served other short-term project goals and their success was uncertain. One such example was given by the Game-AC partner who wanted to launch the evaluation in a school context that had limited access to technology. Facing pragmatic obstacles encouraged a new action that, if successful, could impact on national teaching practices:

"We have been talking to [a non-profit organization] here. We're saying that we'd like them to test the game as well, but they say of course that they don't have tablets for that. So, we have actually agreed that we might want to talk to the Ministry of Education together to try and get more resources for dyslexics... If we can justify that this game will help students here in a sense that would change policies in education, in our country for instance." 
This is a preprint of an article accepted for publication in Journal of the Association for Information Science and Technology copyright (C) 2015 (Association for Information Science and Technology)

Another example came from the SE-NP partner who explained that once a small sample of teachers had tried out the software there was the possibility of a snowball effect within and outside the school:

"They try it in their classroom. If it works really well they then tell all of the teachers and then lots of the teachers pick that up or one of the senior leadership team decides it's a really good idea and forces everyone else to do it... Actually that's altering the practices and what would then happen from there is that if it was effective school-wide the Heads then take it to their cluster meetings. So, its like a slow grind of educational development and change."

Moreover, a teacher participant in one of the participating schools within the HCI-AC research, built upon expertise gained during the evaluation phase of the software to put together a case for support to purchase tablets at her school. The impact of these activities was often extrinsic to the technology developed in the project and had the potential to be long-lasting.

\section{DISCUSSION}

Increasingly, research is taking place in the context of interdisciplinary and cross-sector collaborations. Though impact has been a core concern in HCI research, it is unclear if or how the diverse values and practices of team members enable or prevent particular pathways to impact. To address this question, the present paper reports on a critical examination of impact in the context of a large-scale European project. Our goal is to support "analytic generalisation" (Flyvbjerg, 2006; Yin, 2013): our case study research allows us to reify meanings of impact by focusing on how they were accomplished in interdisciplinary research, why and what lessons we have learned (Schramm, 1971; Flyvbjerg, 2006). Analysis of our findings reveals three key considerations in relation to the impact of interdisciplinary and cross-sector research. In this section, we discuss these considerations, present the open challenges and wherever possible derive strategies for building viable pathways to impact.Multi-level Perspectives on Impact

Educational technology can be approached from different levels of analysis. Each level focuses on specific actors whose interests can have different implications on how impact is achieved (Selwyn, 2011). Concerned about the use of technology by students, the micro-level, was mentioned by the majority of interviewees: all project partners agreed that developing software with a solid pedagogical underpinning for addressing children's literacy difficulties was the core focus of the project. Despite this, there were tensions within the micro level between researchers who explicitly acknowledged teachers as designers and those who assumed teachers would 'administer' the technological intervention. Given the 'knots' defined within the proposal initially and the zones of expertise promoted by the Technical Academic (Tech-AC) partner early on, those who worked in special education were reluctant to consider other disciplinary perspectives that challenged some of their assumptions. Building on Vines et al. (2013) and their call for more transparency on who benefits from research, we note that these theoretical differences and the research approaches they motivated meant that teachers were defined and included as beneficiaries of the research only by a small part of the consortium.

Meso-level concerns encapsulating the social and organisational structures of educational institutions, and macro-level concerns referring to economic, political and social values, were less discussed during our interviews. For instance, one interviewee proposed overcoming the challenge of working with schools and their related social and cultural barriers by deploying the software through interested members from their professional network. Conversely, the Innovation Industry (IN-SME) partner's professional goal to sell the technology developed meant that they recognised meso and macro-level concerns as an obvious barrier to introducing technology in children's education, while the Special Education Non-Profit (SE-NP) partner also acknowledged that technological fixes would not address children's exclusion from education. Importantly, cultural impacts such as changing the organisational culture of schools and teacher attitudes toward technology can lay the ground for the use of technology in teaching. Despite these two partners' obvious emotional investment in these issues, the importance of defining a strategy for addressing them was not recognised during the course of the project. In agreement with Vines et al. (2013), the beneficiaries had been defined in the funder's call for proposals, prioritizing a focus on types of involvement that supported the design and evaluation of the technological artefact.

The divergence in positions we found is to be expected in scientific collaborations (Olson, et al., 2008). Concerning impact, our findings suggest that the diverse values and goals of interdisciplinary and cross-sector teams can offer a multi-level approach to impact that broadens both impact types and beneficiaries. Within our project, the challenge in achieving this was the lack of a mechanism to articulate and understand disciplinary and professional identities in relation to the types of impact each party aspired to make. Revising project management processes to make such matters transparent can contribute to the goal of fostering multi-level impact. However, our findings also show that aligning interdisciplinary visions of impact will not always be possible and trust is a necessary mechanism that affords researchers with the space to create impact in ways that are meaningful to them in their respective disciplines and professional contexts. 
This is a preprint of an article accepted for publication in Journal of the Association for Information Science and Technology copyright (C) 2015 (Association for Information Science and Technology)

\section{Impact Through Accountable Processes}

Accountability in research ensures that those creating technology "construct an argument for the appropriateness of the process and the trustworthiness of outcomes" (Frauenberger et al., 2015). In other words, accountability encourages a transparent on-going narrative as to what impacts are sought and how. In interpreting our results, we found that the majority of technical project partners relied solely on the pedagogical experts to discuss the software's learning outcomes, carving out distinct zones of responsibility and expertise for themselves that focused on technical contributions. The creation of silos of responsibility by those involved in the technical implementation meant that accountability of ensuring that learning outcomes were supported by relevant functionality was transferred to pedagogical partners (also see Sonnenwald, 2007). This deferred form of accountability however encouraged the Gaming Academic (Game-AC) partner to focus and prioritise academic impact within their discipline. The Game-AC partner whose research relied on user recruitment by education partners, faced insurmountable difficulties to introduce affective modelling processes due to the education partners' lack of support with user recruitment and data collection. This was partly attributable to the practical obstacles involved in gaining access to students. However, special education partners questioned the Game-AC partner's approach on the basis of the perceived misalignment between the Game-AC partner's desired academic contribution and the expected learning impacts of the technology.

Conversely, HCI Academic (HCI-AC) researchers challenged the project's division of roles and expertise by working with children and teachers using PD to understand pedagogical needs. From the perspective of HCI-AC, users' learning about technology, their empowerment and the expectation that some ideas from this process would be carried out in design (Eriksén, 2002, Suchman, 1993) was a social and academic impact they strived to make. However, given the interdisciplinary nature of the project where technical decisions were managed by other partners, the accomplishment of this impact depended in part on other consortium members who were all sceptical to embrace PD. Constituting a new epistemological position to those involved within the project, PD placed more emphasis on process, its contribution to technology specification was not immediately obvious, and it shifted control from the consortium's initial expert-driven view on design to a more democratic design process. HCI-AC researchers recognised that their epistemological, disciplinary values were not shared by others. Participatory processes were accepted, and in fact used by one of the pedagogical partners who was trained accordingly by the HCI-AC, only after the authors recognised their accountability toward the project consortium by demonstrating to them that PD could support the goals of the project while concurrently introducing process-impacts for the participants involved. The mutual understanding that developed validated the use of PD within the project (also see Olson, et al., 2008), while related training opportunities naturally emerged as part of the collaboration (also see Sonnenwald, 2007).

Earlier we argued that multi-level impacts constituted an overlooked opportunity in interdisciplinary, cross-sector research. Our results further reify this to suggest the importance of grounding such impacts in a shared goal, while developing a sense of collective accountability with regards to this goal. One way to achieve this is by legitimising and actively promoting boundary crossing. Our findings also indicate that interdisciplinary research invites various epistemological positions that can challenge views held in other disciplines on how knowledge is created. In ensuring that researchers' commitment to accountability is recognised by those outside their discipline, researchers must thus demonstrate how their epistemological positions and research goals align with the shared outcomes of the research. Our proposal is effectively a form of knowledge exchange through example, which in the current case study fostered other partners' understanding and contribution to process-based impacts. We thus argue that accountabilities to academic peers (i.e. what constitutes noteworthy research within their discipline, creating academic impact), collaborators (i.e. how this research advances project aims and fits within the project timeframe) and beneficiaries (i.e. how this approach benefit end-users, creating social impact) must be carefully negotiated and aligned.

\section{Valuing A Diverse Set Of Sustainable Outcomes}

Edwards (2003) points out that sustainability can apply to micro (individual), meso (organizational) and macro (society) levels. Regarding the macro level, many of our interviewees agreed that commercialisation was the main mechanism for sustainable societal impact. However, academic interviewees' lack of experience and interest in developing effective and robust commercial software promoted assumptions that the research prototype would be straightforward to commercialise by the IN-SME partner upon the end of the project. While the importance of creating sustainable infrastructures has been recently highlighted (Edwards et al., 2010), technical decisions were taken that made sense in the context of a three-year project, but that would require an overhaul in making the software sustainable at a later stage.

Providing a historical perspective on this matter, Adams et al. explain that there is a knowledge gap on how innovative research processes align with commercialisation (Adams et al., 2013). In conceptualising research and innovation, they propose a two-dimensional space: one axis anchored on "innovation-led" and "scalable, sustainable" solutions, and the second axis anchored on "changing current practices" and "enabling existing practices". The authors acknowledge the difficulties involved in balancing pure innovation with sustainable and scalable solutions given the incompatible interests and 
This is a preprint of an article accepted for publication in Journal of the Association for Information Science and Technology copyright (C) 2015 (Association for Information Science and Technology)

values of each endeavour. Innovation is the core value of research projects and as one of our participants mentioned, it is a professional motive within the academic sector. It is therefore not surprising that interviewees from the academic sector devalued sustainability. Nonetheless, as academic researchers are more and more being encouraged to work in innovation projects where the industry perspective is dominant, our findings underscore the importance of bridging these sectors' expectations. The challenge for academic researchers will be to continue to advance knowledge, while fitting with the goals, processes and timescales of commercial projects. Taking the PD approach as an illustrative example, it remains unclear how users' on-going involvement and resultant empowerment can be sustained in the context of a commercial development cycle (also Parsons and Cobb, 2014).

A second barrier to sustainability resulted from the theoretical conflicts described earlier: whereas some partners advocated the understanding and development of technology-driven teaching practices, others conceived of technology as an agent for change. The implication of the latter view was the limited involvement of teachers as beneficiaries of the research and thus the narrow impact of the research on renewing teachers' technology practices, which as Merkel et al. (2004) points out is necessary to promote sustainable outcomes. In summary, project partners' decisions often inhibited the goal to take the technology to market and stemmed either from their institutional values that privilege scholarly knowledge, or their theoretical beliefs. Our findings concur with Ribes and Finholt (2009) who have suggested that such barriers are likely to continue existing as long as sustainable outcomes are not given the appropriate recognition within academic institutions.

Alongside the strong focus on commercialisation, our interviewees pointed also to opportunities for a wider array of sustainable outcomes. These often addressed the micro and macro level and many of them served as a means to an end. Most importantly, they were the outcome of the interdisciplinary nature of the research. Examples included: reusable processes for $\mathrm{PD}$, such as a customisable framework guiding designers in involving neurodiverse children in design; technical components for use in future dyslexia technology projects, such as a fine-grained user profile of dyslexia, both for English and Greek; $a$ research prototype with a data logger providing dyslexia experts with the facility to run controlled experiments whose results can inform evidence-based interventions of dyslexia; policy changes regarding technology use at special education schools in one of the participating countries. We also found that sustainable outcomes included benefits to the consortium such as researcher learning and cultural change within consortium institutions. In line with our findings on commercialization, the lack of currency of these outcomes in academic partners' institutions and the small scale impact they promised to make fostered the view that these impact types were of lesser importance. Nonetheless, as Ribes and Finholt (2009) have argued, sustainability depends on this gamut of smaller impacts including for example changing practices, institutional commitment, policy changes and participant expertise and training. Moreover, unlike long-term sustainable impact which may take years to achieve, these impact types were achievable in the short-term and justifiable given their function to serve other primary goals. An opportunity thus exists for interdisciplinary and cross-sector research projects to plan, recognise and capture these impact types within their research programme as part of an on-going, reflexive research process.

\section{Limitations}

There are three limitations we must recognize with regards to the research approach taken. Firstly, given the lack of availability of some project members, we decided to conduct purposeful sampling resulting in seven interviews with members of the project consortium. Our strategy focused on capturing the breadth of disciplines and sectors across the project. Even though we acknowledge that our study does not account for the perspectives of all project stakeholders, we are confident in our data's authenticity, i.e., in showing how such collaborations elicit multiple perspectives and actions on impact. Secondly, as our methodology section explains, project stakeholders belonged to different organisational contexts described by a constellation of cultural values and institutional practices. Our analysis focused on differences across sectors. A full exploration of each partner's organisational or cultural context was outside the scope of this research and we must thus bear in mind the possible influences of individual partners' context when interpreting the case study findings. Thirdly, as we describe in our methodology section, the case study focused on a research consortium that was formed when evidence of impact was not a prominent requirement in the proposal writing process. Impact was embedded in the proposal as part of the interventionist goals of the project and additionally articulated in the form of a broad exploitation and dissemination work package. In asking whether our conclusions are transferable to other contexts, we recognize that funders who formalize impact at the proposal stage and hereafter may invite individual stakeholders to provide clearer articulations of the impact they aspire to make, as a result encouraging a different set of collaboration dynamics. In the paper, we provide sufficient detail of our research context. This allows future researchers to appraise its transferability to consortia formed under funding schemes that require an impact component.

\section{Concluding Remark}

In conclusion, in this article we reported on a case study of an interdisciplinary and cross-sector research project. Our goal was to understand how the diverse profiles of research members shape the understanding of impact, how this is enacted in the 
This is a preprint of an article accepted for publication in Journal of the Association for Information Science and Technology copyright (C) 2015 (Association for Information Science and Technology)

context of collaborative research and how this enactment shapes impact. Our analysis highlights three areas for further attention in impact planning: exploiting the different identities of researchers to produce multi-level impact, promoting accountability by ensuring that anticipated cross-discipline impacts align with a shared goal across the project and exploiting the range of sustainable outcomes that can emerge as a result of an interdisciplinary research process.

\section{ACKNOWLEDGMENTS}

This research was funded by the EU FP7 ICT programme of research. We thank the three reviewers and Anne-Marie Oostveen (University of Oxford) for their constructive comments which served to improve this work.

\section{FOOTNOTES}

1) The authors would like to highlight that the first and second authors and contributed equally to the writing of this manuscript

2) http://scratch.mit.edu

3) http://www.computingatschool.org.uk/data/uploads/CASPrimaryComputing.pdf

\section{REFERENCES}

Abbott, A., 2014. The system of professions: An essay on the division of expert labor. University of Chicago Press.

Abreu, M., Grinevich, V., Hughes, A., \& Kitson, M., 2009. Knowledge exchange between academics and the business, public and third sectors. UK-Innovation Research Centre.

Adamczyk, P, and Twidale, B., 2007. Supporting interdisciplinary collaboration: requirements from novel HCI education. In Proc. CHI '07. ACM, New York, NY, USA, pp. 1073-1076.

Adams, A., Fitzgerald, E. and Priestnall, G., 2013. Of Catwalk Technologies and Boundary Creatures. ACM Trans. Comput.-Hum. Interact. 20(3:15).

Alpay, L., Giboin, A., \& Dieng, R. (1998). Accidentology: An example of problem solving by multiple agents with multiple representations. In M. W. Van Someren, P. Reimann, H. P. A. Boshuizen \& T. De Jong (Eds.), Learning with multiple representations (pp. 152-174). Oxford, UK: Elsevier.

Boaz, A., Fitzpatrick, S., \& Shaw, B. (2009). Assessing the impact of research on policy: a literature review. Science and Public Policy, 36(4), pp. 255-270.

Bornmann, L., 2013. What is societal impact of research and how can it be assessed? A literature survey. Journal of the American Society for Information Science and Technology, 64(2), pp. 217-233.

Bossen, C., Dindler, C. and Iversen. O., 2010. User gains and PD aims: assessment from a participatory design project. In Proc. PDC '10. ACM, New York, NY, USA, pp. 141-150.

Bossen, C., Dindler, C. and Iversen. O., 2012. Impediments to user gains: experiences from a critical participatory design project. In Proc. PDC'12. ACM, New York, NY, USA, pp. 31-40.

Bromme, R., Rambow, R., and Nückles, M., 2001. Expertise and estimating what other people know: The influence of professional experience and type of knowledge. Journal of Experimental Psychology: Applied, 7(4), pp. 317-330.

Carroll, J., Smith-Kerker, P., Ford, J. and Mazur-Rimetz, S., 1987. The minimal manual. Human-Computer Interaction 3(2), pp. 123-153. 
This is a preprint of an article accepted for publication in Journal of the Association for Information Science and Technology copyright (C) 2015 (Association for Information Science and Technology)

Carroll, J. M., Chin, G., Rosson, M. B., \& Neale, D. C., 2000. The development of cooperation: Five years of participatory design in the virtual school. In Proc. DIS '00. ACM, New YORK, NY, USA, pp. 239-251.

Chetty, M. and Grinter, R., 2007. HCI4D: hci challenges in the global south. In Proc. CHI EA '07. ACM, New York, NY, USA, pp. 2327-2332.

Cummings, N., and Kiesler, S., 2005. Collaborative research across disciplinary and organizational boundaries. Social Studies of Science, 35(5), pp. 703-722.

Dachtera, J., Randall, D. and Wulf. V., 2014. Research on research: design research at the margins: academia, industry and end-users. In Proc. CHI '14. ACM, New York, NY, USA, pp. 713-722.

Druin, A., 2002. The role of children in the design of new technology. Behaviour and information technology, 21(1), pp. $1-25$.

Donovan, C., 2007. The qualitative future of research evaluation. Science and Public Policy, 34(8), October, pp. $585-597$.

Donovan, C., 2008. The Australian Research Quality Framework: A live experiment in capturing the social, economic, environmental, and cultural returns of publicly funded research. In Coryn, CLS. And Scriven, M. (Eds), Reforming the evaluation of research. New Directions for Evaluation, 118, pp. 47-60.

Doucet, A. and Mauthner, N., 2002. Knowing responsibly: Linking ethics, research practice and epistemology. Ethics in qualitative research, Miller, T., Birch, M., Mauthner, M. and Jessop, J. (Eds), Sage:USA, pp. 123-145.

Edwards, P. N., 2003. Infrastructure and modernity: Force, time, and social organization in the history of sociotechnical systems. Modernity and technology, pp. 185-225.

Edwards, P., Jackson, S., Bowker, G. and Knobel, C., 2007. Understanding Infrastructure: Dynamics, Tensions, and Design. Workshop on "History \& Theory of Infrastructure: Lessons for New Scientific Cyberinfrastructures". http://hdl.handle.net/2027.42/49353. Last accessed 30th March 2015.

Edwards, W., Newman, M. and Poole, E., 2010. The infrastructure problem in HCI. In Proc. CHI '10. ACM, New York, NY, USA, pp. 423-432.

Engeström, Y., Engeström, R., \& Vähäaho, T., 1999. When the center does not hold: The importance of knotworking. Activity theory and social practice: Cultural-historical approaches, pp. 345-374.

Eriksén, S., 2002. Designing for accountability. In Proceedings of the second Nordic conference on Human-computer interaction. pp. 177-186. ACM Press.

European Commission, 2014. Horizon 2020. See Standard Proposal Templates accessed from http://ec.europa.eu/research/participants/portal/desktop/en/funding/reference_docs.html\#h2020-call_ptef-pt

Fallman, D., 2003. Design-oriented Human-Computer Interaction. In Proc. CHI '03. ACM, New York, NY, USA, pp. $225-232$

Finholt, T. A., \& Birnholtz, J. P., 2006. If we build it, will they come? The cultural challenges of cyberinfrastructure development. In Managing nano-bio-info-cogno innovations, pp. 89-101. Springer Netherlands.

Flyvbjerg, B. (2006). Five misunderstandings about case-study research. Qualitative inquiry, 12(2), 219-245. 
This is a preprint of an article accepted for publication in Journal of the Association for Information Science and Technology copyright (C) 2015 (Association for Information Science and Technology)

Frauenberger, C., Good, J., Fitzpatrick, G., and Iversen, O. S., 2015. In pursuit of rigour and accountability in participatory design. International Journal of Human-Computer Studies, 74, pp. 93-106.

Friedland, B. and Yamauchi, Y., 2011. Reflexive Design Thinking: Putting More Human In Human-Centered Practices. Interactions.

Geertz, C., 1994. Thick description: Toward an interpretive theory of culture. Readings in the philosophy of social science, pp. 213-231.

Gitau, S., Marsden, G., \& Donner, J., 2010. After access: challenges facing mobile-only internet users in the developing world. In Proceedings of the SIGCHI Conference on Human Factors in Computing Systems, pp. 2603-2606. ACM.

Good, J. and Robertson, J., 2006. CARSS: A framework for learner-centred design with children. International Journal of AI in Education, 16(4), pp. 381-413.

Guha, M., Druin, A. and Fails, J., 2010. Investigating the impact of design processes on children. In Proc. IDC '10. ACM, New York, NY, USA, pp. 198-201.

HEFCE, 2010. Research Excellence Framework impact pilot exercise: Findings of the expert panels. Accessed: http://www.ref.ac.uk/pubs/refimpactpilotexercisefindingsoftheexpertpanels/

Jackson, S. J., Edwards, P. N., Bowker, G. C., and Knobel, C. P., 2007. Understanding infrastructure: History, heuristics and cyberinfrastructure policy. First Monday, 12(6).

Jackson, S. J., Steinhardt, S. B., and Buyuktur, A., 2013. Why CSCW needs science policy (and vice versa). In Proceedings of the 2013 conference on Computer supported cooperative work, pp.1113-1124. ACM.

Klein, J. T., 2008. Evaluation of interdisciplinary and transdisciplinary research: a literature review. American journal of preventive medicine, $35(2)$, pp. S116-S123.

Lane, J., 2009. Assessing the Impact of Seience Funding. Science, Vol 324, pp. 1273-1275.

Lawrence, K. A., 2006. Walking the tightrope: The balancing acts of a large e-research project. Computer Supported Cooperative Work (CSCW), 15(4), 385-411.

Maloney, J., Resnick, M., Rusk, N., Silverman, B. and Eastmond, E., 2010. The Scratch Programming Language and Environment. Trans. Comput. Educ. 10, 4, Article 16.

Massey, C., Alpass, F., Flett, R., Lewis, K., Morriss, S., and Sligo, F., 2006. Crossing fields: The case of a multidisciplinary research team. Qualitative Research, 6(2), pp. 131-147.

Mauthner, N. S. and Doucet, A., 1998. Reflections on a Voice Centred Relational Method of Data Analysis: Analysing Maternal and Domestic Voices in Feminist Dilemmas in Qualitative Research: Private Lives and Public Texts, Ribbens, J. and Edwards, R. (Eds), London: Sage

Merkel, C., Xiao, L., Farooq, U., Ganoe, C., Lee, R., Carroll, J. and Rosson, M.B., 2004. Participatory design in community computing contexts: tales from the field. In Proc. PD '04. ACM, New York, NY, USA, pp. 1549-1558.

Miller, T. R., Baird, T. D., Littlefield, C. M., Kofinas, G., Chapin, F. S., and Redman, C. L., 2008. Epistemological pluralism: reorganizing interdisciplinary research. Ecology and Society, 13(2): 46.

NIH, 2014. Star Metrics. Accessed: https://www.starmetrics.nih.gov 
This is a preprint of an article accepted for publication in Journal of the Association for Information Science and Technology copyright (C) 2015 (Association for Information Science and Technology)

National Research Council. Continuing Innovation in Information Technology. Washington, DC: The National Academies Press, 2012.

The National Science Foundation (NSF), 2014. Proposal and Award Policies and Procedures Guide Part I - Grant Proposal Guide. www.nsf.gov/pubs/policydocs/pappguide/nsf14001/gpgprint.pdf

Olson, G. M., Zimmerman, A. and Bos, N., 2008. Scientific collaboration on the Internet. The MIT Press.

Oostveen, A., E.T. Meyer and B. Pickering (2013) User Involvement in Future Internet Projects. In: A. Galis and A. Gavras (Eds.) Future Internet Assembly 2013: Validated Results and New Horizons. Springer Lecture Notes in Computer Science (LNCS) Vol. 7858, pp. 310-322.

Parsons, S. and Cobb, S., 2014. Reflections on the role of the "users": challenges in a multi-disciplinary context of learner-centred design for children on the autism spectrum. International Journal of Research \& Method in Education, pp. $1-21$.

Penfield, T., Baker, M. J., Scoble, R., and Wykes, M. C., 2013. Assessment, evaluations, and definitions of research impact: A review. Research Evaluation, pp. 1-12.

RCUK, 2014. Typology of Research Impact. http://www.rcuk.ac.uk/RCUKprod/assets/documents/impacts/TypologyofResearchImpacts.pdf

Research Excellence Framework, 2014. http://www.ref.ac.uk

Ribes, D. and Finholt, T. A., 2009. The long now of technology infrastructure: articulating tensions in development. Journal of the Association for Information Systems, 10(5), 2. pp. 375-398.

Russell Group, 2012. The social impact of research conducted in Russell Group universities. Russell Group Papers, Issue 3, 2012. Accessed: http://www.russellgroup.ac.uk/uploads/SociallmpactOfResearch.pdf

Rosen, M., 1991. Coming to Terms with the Field: Understanding and Doing Organizational Ethnography. Journal of Management Studies, 28(1), pp. 1-24.

Royal Society, 2010. The Scientific Century: securing our future prosperity.

Schramm, W., 1971. Notes on Case Studies of Instructional Media Projects. US Department of Health, Education and Welfare: National Institute of Education.

Scoble, R., Dickson, K., Fisher, J., \& Hanney, S., 2009. Research impact evaluation, a wider context: Findings from a research impact pilot. Working Paper. Accessed: http://bura.brunel.ac.uk/handle/2438/3475

Selwyn, N., 2011. Education and technology: Key issues and debates. Bloomsbury Publishing.

Sengers, P. and Gaver, B., 2006. Staying open to interpretation: engaging multiple meanings in design and evaluation. In Proc. DIS '06. ACM, New York, NY, USA, pp. 99-108.

Shklovski, I., and Vertesi, J., 2013. Un-googling publications: the ethics and problems of anonymization. In CHI'13 Extended Abstracts on Human Factors in Computing Systems, pp. 2169-2178. ACM.

Smith, S.O., Ward, V. and House, A., 2011. 'Impact' in the proposals for the UK's Research Excellence Framework: shifting the boundaries of academic autonomy. Research Policy, 40 (10). Pp. 1369 - 1379. 
This is a preprint of an article accepted for publication in Journal of the Association for Information Science and Technology copyright (C) 2015 (Association for Information Science and Technology)

Sonnenwald, D. H., 2007. Scientific collaboration. Annual review of information science and technology, 41(1), pp. 643681.

Star, S. L., and Griesemer, J. R., 1989. Institutional ecology, translations' and boundary objects: Amateurs and professionals in Berkeley's Museum of Vertebrate Zoology, 1907-39. Social studies of science, 19(3), pp. 387-420.

Stebbins, R.A., 2001. Exploratory Research in the Social Sciences. Qualitative Research Methods (48), Sage: USA.

Steinfield, C., Ellison, N., and Lampe, C., 2008. Social capital, self-esteem, and use of online social network sites: A longitudinal analysis. Journal of Applied Developmental Psychology, 29(6), pp. 434-445.

Suchman, L., 1993. Working relations of technology production and use. Computer Supported Cooperative Work, 2(1-2), pp. 21-39.

Sutherland, W. J., Goulson, D., Potts, S. G., and Dicks, L. V., 2011. Quantifying the impact and relevance of scientific research. PloS one, 6(11).

Taylor, N., Cheverst, K., Wright, P. and Olivier, P., 2013. Leaving the wild: lessons from community technology handovers. In Proc. CHI '13. ACM, New York, NY, USA, pp. 1549-1558.

Vanderheiden, G. C., and Jordan, J. B., 2006. Design for people with functional limitations. Handbook of Human Factors and Ergonomics, Fourth Edition, 1407-1441.

Vines, J., Clarke, R., Wright, P., McCarthy, J. and Olivier, P., 2013. Configuring participation: on how we involve people in design. In Proc. CHI '13. ACM, New York, NY, USA, pp. 429-438.

Wilsdon, J., 2011. Knowledge, networks and nations: Global scientific collaboration in the 21st century. The Royal Society.

Yin, R. K., 2014. Case study research: Design and methods. Sage publications.

Younglove-Webb, J., Thurow, A. P., Abdalla, C. W., and Gray, B., 1999. The dynamics of interdisciplinary research teams in academia. The review of higher education, 22(4), pp. 425-440. 